\title{
2 Antibiotic Pollution in Surface Fresh Waters: Occurrence and
}

\section{Effects}

4 Danner, Marie-Claire ${ }^{1 *}$, Robertson, Anne ${ }^{1}$, Behrends, Volker ${ }^{1}$, and Julia Reiss ${ }^{1}$

$5 \quad{ }^{I}$ Department of Life Sciences, Whitelands College, Roehampton University, London SW15 4JD,

6 United Kingdom.

$7 *$ Corresponding author

8

9 Email: dannerm@roehampton.ac.uk

10

11 Keywords: antibiotic, surface water, bioassays, mixtures, food-webs, antibiotic resistance

12

13

14

15

16

17

18

19

20

21

22

23

24

25 


\section{Abstract}

2 Worldwide, antibiotic usage exceeds 100,000 tons per year and there is increasing concern over the fate of these substances. Antibiotics are ubiquitous in the environment and significant concentrations have been detected in fresh waters. In this review, we highlight important aspects of antibiotic pollution in fresh waters: that concentrations of antibiotics in the environment are substantial, that micro-organisms are susceptible to this, that bacteria can evolve resistance in the environment, and that antibiotic pollution affects natural food webs while interacting with other stressors; which taken together poses a number of challenges for environmental scientists.

In the literature, we found examples of considerable antibiotic pollution in fresh waters. In the Americas, antibiotic concentrations of up to $15 \mu \mathrm{g} / \mathrm{L}$ have been measured; with higher concentrations reported from European and African studies (over $10 \mu \mathrm{g} / \mathrm{L}$ and $50 \mu \mathrm{g} / \mathrm{L}$ respectively), and in Asian-pacific countries concentrations over $450 \mu \mathrm{g} / \mathrm{L}$ have been detected.

While these concentrations might not be deemed harmful to humans, non-target freshwater organisms could be affected by them. Bioassays show that some of the antibiotics found in surface waters affect microbes at concentrations below $10 \mu \mathrm{g} / \mathrm{L}$. Among the most potent antibiotics are those that prevail in streams and rivers in these concentrations, such as ciprofloxacin. Sub-lethal concentrations might not kill prokaryotes but contribute to increased bacterial resistance and change the composition of single-celled communities, as demonstrated in laboratory experiments. This has implications for the microbial food web (e.g. interactions among and between bacteria and their protozoan consumers) and by extension, larger organisms and ecosystem health.

The fact that the effects of antibiotics are extremely context-dependent represents a challenge, particularly for in vitro research. We suggest future research avenues, taking into 
1 account food web experiments, antibiotics interacting with one another (and other stressors)

2 and discuss how these can help to answer multi-layered research questions. 


\section{1. Introduction}

2 Antibiotics are antimicrobial drugs that kill or inhibit the growth of bacteria. There are several kinds of antibiotics and they can be classified based on their action mechanisms or chemical structure. They have been used in large quantities for some decades and resistance of pathogens to antibiotics has long been a focal point of research in clinical settings and, in more recent years, in environmental research. The parent compounds of antibiotics, or their metabolites, can be stable enough to bypass water treatment processes and leak into the environment (Kümmerer, 2009), and although diluted by a factor of over one million compared to concentrations in the human body (Jjemba, 2006), the antibiotics dispersed in the environment could have important consequences for both human health and ecosystems. While antibiotics are specifically administered therapeutically to treat pathogen infection and/or prophylactically to boost yields (in livestock farming), non-target organisms (that are part of ecological processes, such as nutrient cycling or degradation of pollutants) are inevitably exposed once antibiotics reach the environment (Flaherty and Dodson, 2005). The resulting concentration of antibiotics entering aquatic systems can interact with the native organisms and can, for example, begin to change the microbial community structure and genetics (e.g., prevalence of resistance genes) (Singer et al., 2016). Prokaryote microalgae (cyanobacteria) can be particularly vulnerable to antibiotics (Cabello, 2006) and continuous exposure of the environment to antibiotics can enhance the selection of resistant bacterial strains, which include potential pathogens (Kümmerer, 2004). Another, much less studied hypothesis is that antibiotics could also have indirect cascading effects on species that are not directly affected by antibiotics but feed on prokaryotes.

This review firstly provides a synopsis of antibiotic concentrations in fresh waters (especially running water - i.e. streams and rivers), highlighting the dominant antibiotics in the open water (as opposed to the sediment). Secondly, we cross-referenced these antibiotic 
1 concentrations with available literature on aquatic organisms' susceptibility in bioassays to

2 estimate whether concentrations found in the field affect freshwater organisms. Thirdly, we

3 look at available data on antibiotic resistance in natural microbial communities in fresh water

4 settings. Finally, we aim to place this evidence into the context of more complex scenarios,

5 such as potential effects of antibiotic pollution for real food webs (involving a whole suite of

6 organisms from prokaryotes to single celled eukaryotes to metazoans) or interactions of

7 antibiotics with each other and temperature. We suggest future research avenues including

8 food web experiments that provide a realistic and rigorous way to demonstrate how micro-

9 pollutants affect microbial assemblages and by extension entire communities. In the following, we build our arguments on existing reviews on this topic such as

11 Carvalho and Santos (2016) and Segura et al. (2015) (both on antibiotic concentrations in fresh waters), Grenni et al., (2018) (antibiotic effects on bacteria in the environment), and on reviews on micro-pollutants in running waters (Hughes et al., 2012; Monteiro and Boxall, 2015). We want to highlight that there is a substantial body of literature on antibiotics in the environment and that we chose examples from that literature that we believe to be relevant and representative.

\section{The sources and fate of antibiotic pollution in fresh water}

There are three major pathways for antibiotics into fresh waters: (1) effluents from

Wastewater Treatment Plants (WWTPs), (2) chemical manufacturing plants and (3) animal husbandry and aquaculture (Kümmerer, 2009; Singer et al., 2016). Wise (2002) estimated antibiotic consumption worldwide to lie between 100,000 and 200,000 ton per annum, with approximatively $50 \%$ used for veterinary medicine and as growth promoters. Global antibiotic consumption by humans alone increased by $36 \%$ between 2000 and 2010 which illustrates that antibiotic pollution is an ever-growing problem (Van Boeckel et al., 2014). 
In general, 50-80\% of total parent compounds is excreted through urine and faeces:

2 higher excretion rates are observed for ciprofloxacin (50 to 80\%) and tetracycline (80 to 90\%), while lower excretion rates are observed for erythromycin (5 to $10 \%$ ), sulfamethoxazole (15 to 30\%) or clarithromycin (25\%) (Mompelat et al., 2009). In wastewater disposal systems, antibiotics can be eliminated through retention in sludge and/or

6 biotic and abiotic degradation. However, breakdown is often incomplete, and antibiotics and

7 their metabolites end up entering the environment (mainly fresh waters such as streams and

8 rivers). The proportion of the parent compound excreted via WWTP effluents can differ 9 greatly among antibiotics and the process used (Monteiro and Boxall, 2015) but Kümmerer and Henninger (2003) found that approximately $70 \%$ of the consumed amount of antibiotics was excreted unchanged from hospitals and households into effluents in Germany. The sorption behaviour of antibiotics (i.e. what they preferentially absorb onto the solid phase) can also be very complex. For example, fluoroquinolones become highly enriched in sewage sludge (Giger et al., 2003) while in the case of sulfonamides, it has been found that elimination by sorption to soil particles is a significant process, meaning that they are preferentially found in wastewater (Heise et al., 2006). Remarkable concentrations of micropollutants are detected in effluent wastewaters. For example, in hospital effluents near the Ter River in Spain, ofloxacin and ciprofloxacin have been found at concentrations of over $13 \mu \mathrm{g} / \mathrm{L}$ (Rodriguez-Mozaz et al., 2015). Östman et al. (2017) in Sweden found ciprofloxacin and erythromycin with concentrations of 1.41 $\mu \mathrm{g} / \mathrm{L}$ and $0.47 \mu \mathrm{g} / \mathrm{L}$ in incoming sewage water and $0.06 \mu \mathrm{g} / \mathrm{L}$ and $0.35 \mu \mathrm{g} / \mathrm{L}$ in treated effluent respectively. From WWTP effluents to The Cache la Poudre River in northern Colorado ampicillin and oxacillin have been reported at concentrations of $86 \mu \mathrm{g} / \mathrm{L}$ and 95 $\mu \mathrm{g} / \mathrm{L}$ respectively (Cha et al., 2006) and from WWTP effluents to the Msunduzi River in 
$1 \mu \mathrm{g} / \mathrm{L}$ respectively (Agunbiade and Moodley, 2016). Much higher concentrations are possible:

2 in the effluent from a wastewater treatment plant serving about 90 bulk drug manufacturers in

3 Patancheru, near Hyderabad in India, ofloxacin and ciprofloxacin have been found at

4 concentrations up to $160 \mu \mathrm{g} / \mathrm{L}$ and $31,000 \mu \mathrm{g} / \mathrm{L}$ respectively (Larsson et al., 2007). This area

5 can be considered as an exception as there is a very large number of industries congregated in

6 a limited area (Larsson, 2014) but nonetheless, the concentrations of antibiotics are

7 alarmingly high.

WWTP effluents and run-off from the terrestrial landscape are the main sources for antibiotic pollution (and other micropollutants) in the open water of streams and rivers. We mainly focus on antibiotic concentrations that can be found in the open water of streams and rivers because data for the open water are more readily available. However, it is worth mentioning that micropollutants such as antibiotics attenuate in the sediment (PeraltaMaraver et al., 2018b; Robertson and Wood, 2010), and that sediment acts as a mechanical and biogeochemical filter ('bioreactor') (Lewandowski et al., 2011). Clearly, the sediment has a critical role in pollution attenuation and removal rates of emerging micropollutants (Peralta-Maraver et al., 2018b, 2018a).

\section{Antibiotic concentrations in open water of streams and rivers}

Previous reviews on concentrations of antibiotics in freshwaters have been published (Carvalho and Santos, 2016; Segura et al., 2015). Our review focusses specifically on studies that reported antibiotic concentrations in surface waters of streams and rivers worldwide, in areas away from WWTP outfalls. In these studies, most of the antibiotic concentrations were measured by targeted liquid chromatography-mass spectrometry (LC-MS), an analytical technique that combines the physical separation capabilities of liquid chromatography with a high sensitivity mass spectrometer (Dinh et al., 2011; García-Galán et al., 2010) (Table 1). 
1 We selected studies where concentration values were higher than the limits of quantification

2 and the sample was clearly identified as surface water.

We found 54 studies in total, from 28 different countries (Table 1). The countries with the highest number of reports about the occurrence of antibiotics were Spain and China (Table 1). In Europe, some antibiotics were measured at concentrations above $10 \mu \mathrm{g} / \mathrm{L}$ such as sulfapyridine (Díaz-Cruz et al., 2008) and sulfamethoxazole (Ginebreda et al., 2010), both in Spain (Table 1). Based on the data available to us, Spain is the European country with the highest number of studies reported (15) and with the highest concentration of antibiotics (1.3 $\mu \mathrm{g} / \mathrm{L}$ on average found in surface waters - for European full data see the electronic supplementary material, table S1).

In the Americas, antibiotic concentrations of around $2 \mu \mathrm{g} / \mathrm{L}$ or less were found in fresh waters, except for sulfadimethoxine, found at $15 \mu \mathrm{g} / \mathrm{L}$ in Kansas, USA (Lindsey et al., 2001), and most of the publications were from the United States of America (Table 1). The highest antibiotic concentrations were found in Asia: oxytetracycline has been found at 484 $\mu \mathrm{g} / \mathrm{L}$ more than $20 \mathrm{~km}$ downstream from a WWTP in the Xiao river (Li et al., 2008).

Sulfamethazine has been reported with a concentration of $19 \mu \mathrm{g} / \mathrm{L}$ in Vietnam (Managaki et al., 2007), and aus der Beek et al. (2016) reported ofloxacin and sulfamethoxazole at 17.7 $\mu \mathrm{g} / \mathrm{L}$ and $14.3 \mu \mathrm{g} / \mathrm{L}$ respectively (Table 1). Finally, in Africa, sulfamethoxazole was reported at $53.8 \mu \mathrm{g} / \mathrm{L}$ in Mozambique (Segura et al., 2015) and at $38.9 \mu \mathrm{g} / \mathrm{L}$ in Kenya (Madikizela et al., 2017) (Table 1). In South African streams and rivers, nalidixic acid and ciprofloxacin were reported with concentrations of $23 \mu \mathrm{g} / \mathrm{L}$ and $14 \mu \mathrm{g} / \mathrm{L}$ respectively (Agunbiade and Moodley, 2016) (Table 1).

Segura et al. (2015) reported that the mean concentration of antibiotics in contaminated fresh waters was significantly higher in low income countries, due to a lack of sanitation facilities and wastewater treatment. We found similar results as the mean 
1 concentration of antibiotics was $17.7 \mu \mathrm{g} / \mathrm{L}$ and $11.3 \mu \mathrm{g} / \mathrm{L}$ in Asia-Pacific and Africa

2 respectively, and $0.9 \mu \mathrm{g} / \mathrm{L}$ and $0.4 \mu \mathrm{g} / \mathrm{L}$ in America and Europe (for Europe: mean

3 concentration based on the reports in electronic supplementary material, table S1). It is worth

4 pointing out that consumption of antibiotics is higher in high-income countries (Klein et al., 5 2018).

$6 \quad$ The studies paint a highly divergent picture, with different antibiotics found at vastly

7 different concentrations but overall concentrations found in surface waters are lower than

8 concentrations found in effluent wastewaters as pointed out in section 2. Furthermore, a

9 standardised panel for the determination of antimicrobial concentrations in the environment

10 has not yet been agreed on in these countries. Nevertheless, the presence of these

11 antimicrobials and their often-unquantified metabolites is of concern.

\section{Toxic potential of antibiotics}

While it is important to know about the presence and concentrations of antibiotics occurring in fresh waters, it is arguably more important to determine whether the compounds have an effect on the different organismal groups inhabiting the environment. Here, the challenge of replicating the complex natural setting in the laboratory becomes apparent. For bacteria, antibiotic susceptibility profiles are obtained under highly reproducible rich media conditions, to eliminate variation between laboratories, because antibiotic susceptibility is highly condition dependent (Greulich et al., 2015). It is questionable whether these profiles can be readily applied to natural freshwater systems where nutrients are often limited. To evaluate the antibacterial toxicity effects on non-target organisms, specific tests measure either acute effects (often cell death or mortality rates, i.e. antibiotics short term effects) or chronic toxicity (often exposure over a prolonged period of time, growth index or reproduction, i.e. long term effects of antibiotics) (Soares et al., 2012). Multi-component 
1 bioassays typically measure the overall response to a substance and assess the impact on

2 different levels of biological organisation such as community, population, individual and/or

3 sub-organism level (Carvalho et al., 2014). Bioassay measures are the $\mathrm{EC}_{50}$ (concentration

4 giving half of the maximum response), $\mathrm{LC}_{50}$ (concentration giving half lethality), $\mathrm{IC}_{50}$

5 (concentration giving half inhibition), NOEC (concentration with no observed effect) and

6 LOEC (concentration giving the lowest observed effect). Such tests are generally regarded as

7 good indicators of the potential risks posed by individual chemicals, but there is no model

8 system and by design they fail to take into account chemical-chemical or chemical-

9 organismal interactions.

The database "Wikipharma" (Molander et al., 2009) compiles publicly available ecotoxicity data for Active Pharmaceutical Ingredients (APIs), including antibiotics (www.wikipharma.org, DOI: 10.1016/j.yrtph.2009.08.009). The rationale for choosing "Wikipharma" as an example for a database was that it is a free, interactive, comprehensive and up-to-date database on the effects caused by pharmaceuticals on non-target animals (Molander et al., 2009). Our aim was not to perform a meta-analysis as such but to illustrate that many antibiotics show high toxicity in bioassays with freshwater organisms (single celled pro- and eukaryotes and multicellular organisms). We searched the database for studies on toxicity tests using antibiotics and freshwater organisms and found 49 publications, which - taken together - report the effects of 47 antibiotics in 513 different experiments. We define one experiment as the measured effect of one antibiotic concentration on one species or on bacterial communities (see the electronic supplementary material table S2). More than 50\% of these bioassay experiments included non-target bacteria, including 71 studies on cyanobacteria. The antibiotics most studied in bioassays were trimethoprim (57 experiments $-11 \%)$, sulfamethoxazole and oxytetracycline (48-9\%), chloramphenicol (35-7\%), erythromycin $(31-6 \%)$, ofloxacin $(27-5 \%)$, and ciprofloxacin and ampicillin $(25-5 \%)$, the 
1 remaining antibiotics were studied in less than 20 experiments (see the electronic supplementary material table S2).

Most of the antibiotics used in ecotoxicological assays were found in fresh waters

(Fig. 1) and in most cases $\mathrm{EC}_{50}$ was reported. The Commission of the European Communities classifies chemicals with an $\mathrm{EC}_{50}$ between 10 and $100 \mathrm{mg} / \mathrm{L}$ as harmful, from 1 to $10 \mathrm{mg} / \mathrm{L}$ as toxic and those under $1 \mathrm{mg} / \mathrm{L}$ as very toxic to aquatic organisms (European Commission, 1996; Petrie et al., 2014) (Table 2). Interestingly, for unicellular organisms, the average $\mathrm{EC}_{50}$ was below $1 \mathrm{mg} / \mathrm{L}$ (i.e. the antibiotics were 'very toxic') and in some cases the $\mathrm{EC}_{50}$ was measured at much lower concentrations (Fig. 1A) and within the range found in streams and rivers with antibiotic pollution (Table 1). Half of the studies that used concentrations below $10 \mu \mathrm{g} / \mathrm{L}$ showed that these concentrations were harmful to single-celled pro- and eukaryotes. For instance, some of these bioassay studies revealed that low concentrations (in the $\mu \mathrm{g} / \mathrm{L}$ range) of antibiotics can have negative effects on bacteria (Table 2) and a third of the tests on bacteria, looking at survival or bioluminescence (i.e. acute toxicity), measured $\mathrm{EC}_{50}$ below 1 $\mathrm{mg} / \mathrm{L}$ or even in the microgram range. For example, Ando et al. (2007) tested the effects of ampicillin on the cyanobacterium Microcystis aeruginosa, with a range of concentrations from $30 \mathrm{ng} / \mathrm{L}$ to $200 \mathrm{mg} / \mathrm{L}$, and measured $\mathrm{EC}_{50}$ at only $0.2 \mu \mathrm{g} / \mathrm{L}$ (see Table 2).

According to the Wikipharma data, $25 \%$ of all studies estimating the effects of antibiotics on eukaryotic, single celled algae, found $\mathrm{EC}_{50}$ values below $1 \mathrm{mg} / \mathrm{L}$ and 12 studies even report $\mathrm{EC}_{50}$ to be below $100 \mu \mathrm{g} / \mathrm{L}$ (electronic supplementary material table $\mathrm{S} 2$ ). The tests performed were measured as growth inhibition, usually after 72 hours. Two studies, one investigating the effects of amoxicillin on Synechococcus leopolensis and one of clarithromycin on Pseudokirchneriella subcapitata showed very high sensitivity of eukaryotic algae to antibiotics, as they found the $\mathrm{EC}_{50}$ to be $2 \mu \mathrm{g} / \mathrm{L}$ (Andreozzi et al., 2004; Isidori et al., 2005) (Table 2). 
In the Wikipharma database, multicellular species generally showed $\mathrm{EC}_{50}$ values

2 above $1 \mathrm{mg} / \mathrm{L}$ and all average values were in 10-1000 mg/L range (Fig. 1B). Therefore, they seem less susceptible to antibiotics and are possibly not influenced by those concentrations measured in running waters (Table 1) but the database showed notable exceptions, such as duckweed. Multicellular plants used in bioassays were represented by duckweed and 14 experiments using this plant found an $\mathrm{EC}_{50}$ for growth inhibition under $1 \mathrm{mg} / \mathrm{L}$ (Brain et al., 2004; Robinson et al., 2005) (Table 2).

Metazoans have also extensively been used in bioassays reported in Wikipharma

(Table 2), including species belonging to: fish (40 studies), molluscs (16), crustaceans (117), rotifers (19) and cnidarians (4). Low levels of antibiotics directly in contact with invertebrates (such as crustaceans, cnidarians and molluscs) did not affect their degree of survival, their reproduction, nor their sex-ratio, with the exception of a few cases, and only five of the 137 experiments measured an $\mathrm{EC}_{50}$ lower than $1 \mathrm{mg} / \mathrm{L}$ (Calleja et al., 1993; Isidori et al., 2005). organisms (both pro- and eukaryotes) are most susceptible to low antibiotic concentrations. These findings are backed up by more studies and reviews. For example, Bengtsson-Palme and Larsson (2016) reviewed the effects of antibiotics on clinically relevant bacteria and found the lowest minimal inhibitory concentrations (MIC) at $2 \mu \mathrm{g} / \mathrm{L}$ for 13 antibiotics, corresponding to the lowest concentration tested. Le Page et al. (2007) calculated relative species sensitivity and found that prokaryotes were the most sensitive to antibiotics, and Valitalo et al. (2017) who reviewed the toxicological impact of antibiotics on microscopic aquatic organisms found that cyanobacteria and ammonium oxidizing bacteria were the most sensitive to antibiotics in general. Therefore, natural microbial communities are the most vulnerable to antibiotics discharge in the aquatic environment (as also pointed out by Grenni et al. (2018)). 

database, we can identify some particularly problematic antibiotics in terms of their occurrence in fresh waters and their toxicity. While some of the antibiotics affecting those organisms are not frequently found in the environment, some others like ciprofloxacin and

5 ofloxacin can be found at relatively high concentrations in fresh waters (aus der Beek et al., 6 2016; Feitosa-Felizzola and Chiron, 2009; Ginebreda et al., 2010) (Table 1) and are among

7 the most potent antibiotics at low concentrations (Bengtsson-Palme and Larsson, 2016).

8 Studies found that ciprofloxacin was inhibiting the growth of the cyanobacteria Mycrocystis 9 aeruginosa at $5 \mu \mathrm{g} / \mathrm{L}$ (Halling-Sørensen et al., 2000) and $17 \mu \mathrm{g} / \mathrm{L}$ (Robinson et al., 2005). This antibiotic was found in fresh waters at concentrations in a similar range: $14.33 \mu \mathrm{g} / \mathrm{L}$ in South Africa (Agunbiade and Moodley, 2016), and 9.66 $\mu \mathrm{g} / \mathrm{L}$ in France (Feitosa-Felizzola and Chiron, 2009) (Table 1). Ofloxacin can inhibit the growth of the bacterium Vibrio fischeri at $0.9 \mu \mathrm{g} / \mathrm{L}$ and the algae Pseudokirchnella subcapitata at $4.74 \mu \mathrm{g} / \mathrm{L}$ (Table 2), and was detected up to $17.7 \mu \mathrm{g} / \mathrm{L}$ in Asia (aus der Beek et al., 2016) and up to $8.7 \mu \mathrm{g} / \mathrm{L}$ in Spain (Ginebreda et al., 2010). Similarly, chloramphenicol, erythromycin, norfloxacin, oxytetracycline, streptomycin, and tylosin are classified as 'very toxic' for aquatic organisms concentrations of over $1 \mu \mathrm{g} / \mathrm{L}$ in fresh waters (Table 1 ).

Bioassays are useful to study the toxicity of new pharmaceutical compounds and the $\mathrm{EC}_{50}$ data give us some indication of the antibiotics' toxicity in an environmental context, however, they do not give information on the effect antibiotics can have in a complex natural system. Also, they do not demonstrate that prokaryotes have the ability to metabolise antibiotics and to evolve in response to antibiotic pollution.

\section{Antibiotic resistance in natural bacterial communities}


1 Standard bioassays do not provide information about microbial resistance, but we know that

2 environmental antimicrobials can act in that way. For instance, many studies have linked antibiotic occurrence in wastewater and antibiotic resistance in WWTP impacted streams

4 (Guo et al., 2017; Schwartz, 2003). Significant correlations are found between the exposure

5 to antibiotics and their corresponding antibiotic resistance genes (ARGs), and the selective

6 pressure for ARGs increase with the concentrations of antibiotics (Li et al., 2012; Rodriguez-

7 Mozaz et al., 2015). It is known that very low antibiotic concentrations (10-100 times below

8 clinically determined minimum inhibitory concentrations) can increase the relative

9 abundance of resistant bacteria and select for resistance by promoting the rate of adaptive evolution (Friman et al., 2015; Gullberg et al., 2011; Lundström et al., 2016).

The emergence of resistance to antimicrobial compounds such as antibiotics is a natural process that has its origins, much as many antibiotics themselves, in inter-species competition in natural environments. It is not surprising, therefore, that bacteria resistant to antibiotics have been found in relatively pristine aquatic and soil environments. A seminal study by Dantas et al. (2008) showed that communities of soil bacteria were able not just to tolerate antibiotics, but to use them as their only source of carbon.

In the clinical context, near consensus has been reached that overuse of available antibiotics combined with the failure to discover new ones is likely to be one of the key challenges of the healthcare sector in the $21^{\text {st }}$ century (Piddock, 2012). Most research has, understandably,focussed on this issue, elucidating genetic determinants of secondary resistance, i.e. mutations that confer increased tolerance to the antibiotic upon exposure to it. This differs from primary or intrinsic resistance that can have a number of reasons, for example the inability of most penicillins to reach their target site in Gram-negative bacteria. Mechanisms of resistance, e.g. degradation or modification of the antibiotic, upregulation of efflux pumps, modification of the target enzyme/substructure rendering the antibiotic useless 
1 and ways for genetic dissemination between bacteria via horizontal gene transfer (HGT) are

2 well understood (Blair et al., 2014).

While the potential for wide-spread resistance can therefore be regarded as near

4 ubiquitous, the dynamics promoting and limiting the spread of resistance across bacterial

5 populations in the natural environment, both within and between species are less well

6 understood. Importantly, the effect of sublethal levels of antibiotics and resulting

7 physiological and phenotypic adaptations, which are governed by environmental factors and

8 also greatly influence (future) resistance potential have recently gained increased attention

9 (Dörries et al., 2014; Fernández et al., 2011).

It is important to determine dynamics promoting and limiting the spread of resistance across bacterial populations in the natural environment, and to identify the environments where an increase of ARGs can occur. Chemicals driving resistance to antibiotics can include - in addition to antibiotics themselves - biocides such as disinfectants, metals and phytochemicals (Friedman, 2015; Gullberg et al., 2014; Pal et al., 2015; Wales and Davies, 2015). Moreover, new research is showing that microplastic can be a vehicle for antibiotics and resistance genes in aquatic ecosystems (Arias-Andres et al., 2018; McCormick et al., 2014). In contrast with other chemical pollutants, bacterial contaminants and their ARGs are capable of persisting and spreading in the environment, and ultimately could transfer their resistance to human pathogens (Bengtsson-Palme et al., 2018; Berendonk et al., 2015). Integrating the capacity of ARGs to transfer from contaminated sources to pathogenic bacteria into risk assessment is a considerable challenge and we also need to be able to test for the occurrence of resistance determinants in the environment (Berendonk et al., 2015). Several studies are looking into the effects of sub-inhibitory concentrations of antibiotics in complex aquatic bacterial communities. Quinlan et al. (2011) exposed a stream biotic community to tetracyclines $(0.5-100 \mu \mathrm{g} / \mathrm{L})$ and found changes in antibiotic resistance, 
1 bacteria abundance and productivity after seven days. Lundstrom et al. (2016) also tested the

2 effects of tetracyclines on biofilms $(0.1-1000 \mu \mathrm{g} / \mathrm{L})$ and found an increase in antibiotic

3 resistance bacteria at $10 \mu \mathrm{g} / \mathrm{L}$ and changes in the biofilm taxonomic composition The

4 development of antibiotic resistance in natural microbial communities is an indirect effect of

5 antibiotics in the environment but they can also have direct effects on the microbial

6 community structure and functioning. Bactericides can cause the disappearance of microbial

7 populations and change the entire bacterial community. Proia et al. (2013) found alterations

8 in the bacterial community composition when exposed to a mixture of 16 antibiotics

9 (concentrations ranging from 0.005 to $1.5 \mu \mathrm{g} / \mathrm{L}$ ) with an increase in Actinobacteria and

10 Laverman et al. (2015) found an effect on bacterial community structures when exposed to

11 vancomycin $(1000 \mu \mathrm{g} / \mathrm{L})$ in river sediments downstream of a WWTP.

Low concentrations of antibiotics can also play an important role in the structure of

biofilms, for example, low concentrations of the antibiotic tobramycin $(50-1000 \mu \mathrm{g} / \mathrm{L})$

induced biofilm formation in Pseudomonas aeruginosa by modulating the aminoglycoside resistance gene which also regulates cell surface adhesiveness (Hoffman et al., 2005). The effect of sub-lethal levels of antibiotics and resulting physiological and phenotypic adaptations, which are governed by environmental factors, have recently gained increased attention (Dorries et al., 2014; Fernández et al., 2011). Furthermore, physiological and genetic adaptations to antibiotic stress do not happen in isolation, but are often tied to changes in other bacterial behaviours such as virulence (Behrends et al., 2013; Martínez and Rojo, 2011; Watkinson et al., 2007; Yeung et al., 2011).

\section{Evaluation of antibiotics under more complex and realistic scenarios}

Our literature search shows that antibiotic concentrations measured in fresh waters, despite concentrations being well below clinically-relevant levels, are very likely to have direct, and 
1 indirect, effects on at least the microbial component of freshwater communities.

2 Environmental scientists are now challenged to show if antibiotic loadings can be detrimental

3 for freshwater communities - as a mixture and under global change scenarios. To capture the

4 true effects of antibiotic impacts on whole communities, and the ecosystem processes they

5 drive, we propose three major future research avenues: i) food webs, ii) antibiotic mixtures

6 and iii) interaction with other stressors such as temperature (Fig. 2), as we outline in the

7 following paragraphs.

The impact of antibiotic pollution on bacteria and aquatic food-webs is likely to be substantial but is complex to determine. While standard bioassays are a valid tool to elucidate the effects of one contaminant on one single species, they generally do not provide information as to how antibiotic exposure influences species assemblages and therefore ecosystem functioning. Sub-inhibitory concentrations of antibiotics can have potential effects on species interactions such as changes in population dynamics and bacterial community composition which can lead to changes in trophic interactions but we are still lacking a population-level perspective (Grenni et al., 2018; Hiltunen et al., 2017). A recent study also found that cooperative communities (i.e. when metabolites produced by one organism are used as nutrients or energy source by another) are more susceptible to antibiotics and as cross-feeding is nearly ubiquitous in microbial communities, low antibiotic concentrations might have a stronger effect than previously thought (Adamowicz et al., 2018).

In addition to bacteria interacting with other bacteria, important interactions in natural microbial communities are those with protozoan predators. Protozoans are the most abundant predators feeding on bacteria and can have a profound effect on bacterial abundance. There are experiments showing that protozoan predators and antibiotic resistance are linked. One study shows that antibiotics can lead to cascading indirect effects in species in other trophic levels (Friman et al., 2015). This study used the bacterium Pseudomonas fluorescens and its 
1 protozoan consumers (the ciliate Tetrahymena pyriformis and the flagellate Chilomonas

2 paramecium) to explore the effects of $40 \mu \mathrm{g} / \mathrm{L}$ of gentamicin and found that bacteria

3

4

5

6

7

increased resistance to both antibiotics and predators in a manner dependent on the antibiotic concentration (Friman et al., 2015). The bacterial adaptation cascaded through the food web leading to a reduced predator-prey abundance ratio, which increased the instability of populations and lowered the predator community (Friman et al., 2015). In another study the protozoan predator Tetrahymena termophila increased the persistence and spread of an antibiotic resistance plasmid in populations of the bacterial pathogen Serratia marcescens (Cairns et al., 2016).

In other food web studies including metazoan consumers, Quinlan et al. (2011) looked at the effect of tetracycline in stream mesocosms and observed a decrease in bacterial abundance but also a reduction in the algal periphyton biomass and nematode abundance. Additionally, they showed that at the highest dose of tetracycline $(10 \mu \mathrm{g} / \mathrm{L}$ and $100 \mu \mathrm{g} / \mathrm{L})$, and after 28 days of non-exposure, the bacterial productivity recovered but not the abundance of bacteria, algae and nematodes (Quinlan et al., 2011). Little is known about the extent that antibiotics are taken up and redistributed among different types of organisms within a food web. A recent study investigated the bioconcentration of trimethoprim over several months in an aquatic food web but they did not detected the antibiotic in the biota (Lagesson et al., 2016). Simple laboratory experiments could explore whether antibiotics change the composition of microscopically small aquatic communities - consisting of bacteria, viruses and protists (Fig. 2; e.g. following the approach used by Friman et al. (2015)). Laboratory cultures could even include larger invertebrates (such as microscopically small crustaceans) to explore how changes in the microbial food web influence the reproduction of larger invertebrates. Certainly it is important to expand these experiments to the 'real world' and natural biofilms are an ideal system to test the effects of antibiotics (Lundström et al., 2016; 
1 Quinlan et al., 2011). We believe an important focus is predator-prey oscillations with prey

2 that is evolving resistance (see Fussman et al., 2014 for an example of a microcosm set-up

3 and data analysis).

Another complex angle to antibiotic pollution in the environment is that organisms and food webs are faced with 'antibiotic cocktails'. Different classes of antibiotics are typically detected simultaneously in fresh water (Table 1) and therefore, aquatic organisms are exposed to mixtures of antibiotics. The individual concentrations of antibiotics that are measured in the environment might be low, but the combined concentrations could result in significant toxicity to aquatic organisms. For example, in the Llobregat River basin in Spain, four antibiotics were analysed (erythromycin, sulfamethoxazole, trimethoprim and ofloxacin) with very low individual concentrations but with a total concentration of $2.4 \mu \mathrm{g} / \mathrm{L}$ (LópezRoldán et al., 2010).

Chemicals in mixtures potentially interact with each other, in synergy or antagonistically. It is therefore essential to investigate the potential interactions between antibiotics in the environment but only a few studies have done this. A theoretical link between the toxicity of the individual antibiotics and the effects of a mixture would allow the prediction of the effects of antibiotic mixtures on aquatic organisms. Two principle concepts, the concentration addition (CA) and the independent action (IA), are often applied for the assessment of pharmaceutical mixtures in the environment (Backhaus, 2014).

For example, the mixture toxicity of ten quinolones (from $14 \mu \mathrm{g} / \mathrm{L}$ to $1020 \mu \mathrm{g} / \mathrm{L}$ ) on the test organism Vibrio fischeri, was estimated using these two concepts and results indicated that the mixture was best predicted with the concentration addition (Backhaus et al., 2000). González-Pleiter et al. (2013) also showed that the combined effect can be 'more than the sum of its parts' by testing the effects of antibiotics used singly, binary and in mixtures of four and five antibiotics. The toxicological interactions of the antibiotics were analysed using 
1 the combination index $(\mathrm{CI})$ and they showed that the combination of erythromycin and

2 tetracycline had a synergistic effect on the green algae Pseudokirchneriella subcapitata at

3 environmentally relevant concentrations (González-Pleiter et al., 2013). Erythromycin and

4 tetracycline added together inhibited the growth of the algae at only $1 / 8^{\text {th }}$ of their individual

5 inhibition concentrations. However, to date, synergistic or antagonistic effects have rarely

6 been observed in multi-components mixtures.

The individual concentrations of antibiotics, which are measured in the environment,

8 can be low but the combined concentrations could result in significant toxicity for aquatic

9 organisms (Fig. 2). An example for a study that attempted a more complex approach comes

10 from Bundschuh et al. (2009), who tested the effects of antibiotic mixtures with

sulfamethoxazole, trimethoprim, erythromycin, roxithromycin and clarithromycin on a decomposer detritivore system (the freshwater crustacean Gammarus fossarum feeding on leaves colonised by bacteria and fungi). They found that fungal biomass was higher at a total antibiotic concentration of $200 \mu \mathrm{g} / \mathrm{L}$ and thus Gammarus preferred leaves 'contaminated' with this antibiotic cocktail (Bundschuh et al., 2009). It was suggested that the antibiotic mixture inhibited bacterial growth, which reduced competition for fungi and therefore promoted fungal growth (Bundschuh et al., 2009) but the design of the experiment did not allow mechanisms to be extracted.

It is essential to investigate the potential interactions between antibiotics in the environment. These questions could be addressed in experiments that mirror the logic of biodiversity-ecosystem functioning research, where the effects of single vs. multi-species treatments on ecosystem processes have been assessed (Lawrence et al., 2012; Perkins et al., 2015; Reiss et al., 2011, 2010, 2009). In analogy to these experiments, it is possible to run laboratory experiments with antibiotic mixtures and to investigate their single- and mixture effects, both on individual species (bacteria) or mini food webs. As a response variable, we 
1 consider the adaptation of bacteria to antibiotic mixtures to be a priority research focus as

2 adaptation to antibiotics can induce changes in the bacterial community and bacteria consumers can be susceptible to them.

In ecosystems, the effects of antibiotics are complex and context-dependent, as

5 highlighted by taking food webs and mixtures into account, and environmental scientists are

6 faced with the fact that antibiotics are not the only stressors in the system. The rise of

7 'ecological surprises' in the primary scientific literature highlights the growing uncertainty

8 over the cumulative impacts of multiple novel and extreme environmental changes, or 'stressors' (Jackson et al., 2016). Ecological surprises are unexpected findings on the combined effects of stressors such as synergism or antagonism. The organisms in the environment are not only exposed to climate change or land use or pollution alone but simultaneously to a multitude of stressors (Fig. 2). If those other stressors have an impact on the diversity of microbial communities, it could affect the spread of antibiotic resistance genes via HGT as species composition and diversity can be a major factor determining how resistance genes spread (Tamminen et al., 2012). For example, a study shows that plasmid transfer is likely to occur to abundant strains and to low-abundance strains in the presence of a more structured spatial environment (Cairns et al., 2018). This study also suggests that plasmid transfer is more likely to happen to more bacterial strains if antibiotics are present (Cairns et al., 2018).

Therefore, it is important to consider how other factors, such as temperature, change the effects of antibiotics. Temperature is a key factor to include in antibiotic studies because both chemical reactions, and the metabolic activity of freshwater organisms, are governed by strict physical laws. In aquatic ecology, theoretical frameworks that include temperature and traits of organisms already exist and can explain how communities respond to temperature changes (Perkins et al., 2015). The use of microcosms, mesocosms and field experiments 
1 have improved our ability to predict effects of contaminants on higher levels of biological

2 organisation (Thompson et al., 2015) as we can test complex, multifactorial hypotheses

3 concerning interactions between the contaminants and environmental factors.

\section{7. Concluding remarks}

6 In this paper, we illustrate that antibiotic pollution in fresh water is ubiquitous and that

7 concentrations in the field are substantial; that many antibiotics are toxic for fresh water

8 organisms from bacteria to multicellular organisms; and that even sub-lethal concentrations

9 have the ability to induce changes in freshwater communities via bacterial resistance. This

10 has knock-on effects for species interactions within the entire fresh water community and is

11 complicated by the fact that antibiotics interact with each other and other stressors. Clearly, freshwater ecologists have the tools to show how antibiotic pollution has, and will, impact upon natural freshwater communities. We believe that it is possible to run experiments that can build on recent research (such as protozoans grazing on adapted bacteria) to find out under which scenarios antibiotics affect natural communities (e.g. competition between prokaryotes and fungi) and how antibiotic effects can cascade from prokaryotes to the entire ecosystem.

It is obvious that antibiotic mixtures can have an effect on important ecosystem processes such as organic matter decomposition in stream ecosystems that are also experiencing stressors such as species loss, habitat alteration and warming. Further, we should also keep in mind that antibiotics are not the only substances found in the fresh water and that complex chemical mixtures with other pollutants should be tested under environmentally relevant scenarios.

Going forward, we believe some general considerations can help future studies.

Firstly, in a food web context, we have to consider predator-prey oscillations with prey that is 
1 evolving resistance. Secondly, in the field, the combined concentration of antibiotics can be

2 high but whether effects are synergistic, additive or antagonistic depends on the particular

3 antibiotics. Therefore, it is critical to remember that for mixtures of antibiotics the whole

4 effect might be different from the sum of its parts. Thirdly, it is essential to move beyond a

5 bioassay approach and to consider the context-dependency of sub-lethal antibiotic

6 concentrations (i.e. realistic field concentrations), to assess fluctuations within the microbial

7 food web through time and to estimate how interactions change with temperature and other

8 anthropogenic stressors.

\section{Data accessibility}

11 The datasets supporting this article have been uploaded as part of the supplementary material.

\section{Competing interests}

13 We declare no competing interests.

14 Authors' contributions

M-CD carried out the literature search, data compilation, and wrote the manuscript; JR, VB and AR wrote the manuscript; M-CD and JR conceived of the study. All authors gave final

17 approval for publication.

\section{Acknowledgments}

19 M-CD was supported by a University of Roehampton, London research studentship and supervised by JR and AR. This project was matched to funding by the European Union's Horizon 2020 research and innovation programme under Marie-Skłodowska-Curie grant agreement No. 641939. We thank five anonymous reviewer whose comments greatly improved this manuscript. 
References

2

3 Adamowicz, E.M., Hunter, R.C., Flynn, J., Harcombe, W.R., 2018. Cross-feeding modulates antibiotic tolerance in bacterial communities. bioRxiv 243949. https://doi.org/10.1101/243949

Agunbiade, F.O., Moodley, B., 2016. Occurrence and distribution pattern of acidic pharmaceuticals in surface water, wastewater, and sediment of the Msunduzi River, Kwazulu-Natal, South Africa. Environ. Toxicol. Chem. 35, 36-46. https://doi.org/10.1002/etc.3144

Ando, T., Nagase, H., Eguchi, K., Hirooka, T., Nakamura, T., Miyamoto, K., Hirata, K., 2007. A novel method using cyanobacteria for ecotoxicity test of veterinary antimicrobial agents. Environ. Toxicol. Chem. 26, 601-6. https://doi.org/10.1897/06195R.1

Andreozzi, R., Caprio, V., Ciniglia, C., de Champdoré, M., Lo Giudice, R., Marotta, R., Zuccato, E., 2004. Antibiotics in the environment: occurrence in Italian STPs, fate, and preliminary assessment on algal toxicity of amoxicillin. Environ. Sci. Technol. 38, 6832-6838. https://doi.org/10.1021/es049509a

Arias-Andres, M., Klümper, U., Rojas-Jimenez, K., Grossart, H.P., 2018. Microplastic pollution increases gene exchange in aquatic ecosystems. Environ. Pollut. 237, 253-261. https://doi.org/10.1016/j.envpol.2018.02.058

aus der Beek, T., Weber, F.A., Bergmann, A., Hickmann, S., Ebert, I., Hein, A., Küster, A., 2016. Pharmaceuticals in the environment-Global occurrences and perspectives. Environ. Toxicol. Chem. 35, 823-835. https://doi.org/10.1002/etc.3339

Backhaus, T., 2014. Medicines, shaken and stirred: a critical review on the ecotoxicology of pharmaceutical mixtures. Philos. Trans. R. Soc. B Biol. Sci. 
2 Backhaus, T., Scholze, M., Grimme, L.H., 2000. The single substance and mixture toxicity of quinolones to the bioluminescent bacterium Vibrio fischeri. Aquat. Toxicol. 49, 49-61.

Behrends, V., Ryall, B., Zlosnik, J.E.A., Speert, D.P., Bundy, J.G., Williams, H.D., 2013. Metabolic adaptations of Pseudomonas aeruginosa during cystic fibrosis chronic lung infections. Environ. Microbiol. 15, 398-408.

Bengtsson-Palme, J., Kristiansson, E., Larsson, D.G.J., 2018. Environmental factors influencing the development and spread of antibiotic resistance. FEMS Microbiol. Rev. 42, 68-80. https://doi.org/10.1093/femsre/fux053

Bengtsson-Palme, J., Larsson, D.G.J., 2016. Concentrations of antibiotics predicted to select for resistant bacteria: Proposed limits for environmental regulation. Environ. Int. 86. https://doi.org/10.1016/j.envint.2015.10.015

Berendonk, T.U., Manaia, C.M., Merlin, C., Fatta-Kassinos, D., Cytryn, E., Walsh, F., Bürgmann, H., Sørum, H., Norström, M., Pons, M.N., Kreuzinger, N., Huovinen, P., Stefani, S., Schwartz, T., Kisand, V., Baquero, F., Martinez, J.L., 2015. Tackling antibiotic resistance: The environmental framework. Nat. Rev. Microbiol. https://doi.org/10.1038/nrmicro3439

Blair, J.M.A., Webber, M.A., Baylay, A.J., Ogbolu, D.O., Piddock, L.J. V., 2014. Molecular mechanisms of antibiotic resistance. Nat. Rev. Microbiol. 13, 42-51. https://doi.org/10.1038/nrmicro3380

Brain, R.A., Johnson, D.J., Richards, S.M., Sanderson, H., Sibley, P.K., Solomon, K.R., 2004. Effects of 25 pharmaceutical compounds to Lemna gibba using a seven- day static- renewal test. Environ. Toxicol. Chem. 23, 371-382. https://doi.org/10.1897/02576

Bundschuh, M., Hahn, T., Gessner, M.O., Schulz, R., 2009. Antibiotics As a Chemical 
Stressor Affecting an Aquatic Decomposer-Detritivore System. Environ. Toxicol.

$$
\text { Chem. 28, 197. https://doi.org/10.1897/08-075.1 }
$$

Cabello, F.C., 2006. Heavy use of prophylactic antibiotics in aquaculture: a growing problem for human and animal health and for the environment. Environ. Microbiol. 8, 11371144. https://doi.org/10.1111/j.1462-2920.2006.01054.x

Cairns, J., Jalasvuori, M., Ojala, V., Brockhurst, M., Hiltunen, T., 2016. Conjugation is necessary for a bacterial plasmid to survive under protozoan predation. Biol. Lett. 12, 2015-2018. https://doi.org/10.1098/rsbl.2015.0953

Cairns, J., Ruokolainen, L., Hultman, J., Tamminen, M., Virta, M., Hiltunen, T., 2018. Ecology determines how low antibiotic concentration impacts community composition and horizontal transfer of resistance genes. Commun. Biol. 2018 11 1, 35. https://doi.org/10.1038/s42003-018-0041-7

Calleja, M.C., Persoone, G., Geladi, P., 1993. predictive potential of a battery of ecotoxicological tests for human acute toxicity, as evaluated with the first 50 MEIC chemicals. Altern. to Lab. Anim. ATLA.

Carvalho, I.T., Santos, L., 2016. Antibiotics in the aquatic environments: A review of the European scenario. Environ. Int. https://doi.org/10.1016/j.envint.2016.06.025

Carvalho, R.N., Arukwe, A., Ait-Aissa, S., Bado-Nilles, A., Balzamo, S., Baun, A., Belkin, S., Blaha, L., Brion, F., Conti, D., Creusot, N., Essig, Y., Ferrero, V.E., Flander-Putrle, V., Furhacker, M., Grillari-Voglauer, R., Hogstrand, C., Jonas, A., Kharlyngdoh, J.B., Loos, R., Lundebye, A.K., Modig, C., Olsson, P.E., Pillai, S., Polak, N., Potalivo, M., Sanchez, W., Schifferli, A., Schirmer, K., Sforzini, S., Sturzenbaum, S.R., Softeland, L., Turk, V., Viarengo, A., Werner, I., Yagur-Kroll, S., Zounkova, R., Lettieri, T., 2014. Mixtures of chemical pollutants at European legislation safety concentrations: how safe are they? Toxicol. Sci. 141, 218-233. https://doi.org/10.1093/toxsci/kfu118 
1 Dantas, G., Sommer, M.O., Oluwasegun, R.D., Church, G.M., 2008. Bacteria subsisting on antibiotics. Science 320, 100-103. https://doi.org/10.1126/science.1155157

Díaz-Cruz, M.S., García-Galán, M.J., Barceló, D., 2008. Highly sensitive simultaneous determination of sulfonamide antibiotics and one metabolite in environmental waters by liquid chromatography-quadrupole linear ion trap-mass spectrometry. J. Chromatogr. A 1193, 50-59. https://doi.org/https://doi.org/10.1016/j.chroma.2008.03.029

Dinh, Q.T., Alliot, F., Moreau-Guigon, E., Eurin, J., Chevreuil, M., Labadie, P., 2011. Measurement of trace levels of antibiotics in river water using on-line enrichment and triple-quadrupole LC-MS/MS. Talanta 85, 1238-1245. https://doi.org/10.1016/j.talanta.2011.05.013

Dorries, K., Schlueter, R., Lalk, M., 2014. Impact of antibiotics with various target sites on the metabolome of Staphylococcus aureus. Antimicrob. Agents Chemother. 58, 71517163. https://doi.org/10.1128/AAC.03104-14 [doi]

Dörries, K., Schlueter, R., Lalk, M., 2014. Impact of antibiotics with various target sites on the metabolome of Staphylococcus aureus. Antimicrob. Agents Chemother. 58, 71517163. https://doi.org/10.1128/AAC.03104-14

European Commission, 1996. Technical Guidance Document in Support of Commission Directive 93/67/EEC on Risk Assessment for New Notified Substances and Commission Regulation (EC) No 1488/94 on Risk Assessment for Existing Substances. Part II. Environ. Risk Assessment, Luxemb.

Feitosa-Felizzola, J., Chiron, S., 2009. Occurrence and distribution of selected antibiotics in a small Mediterranean stream (Arc River, Southern France). J. Hydrol. 364, 50-57. https://doi.org/10.1016/j.jhydrol.2008.10.006

Fernández, L., Breidenstein, E.B.M., Hancock, R.E.W., 2011. Creeping baselines and adaptive resistance to antibiotics. Drug Resist. Updat. 14, 1-21. 
https://doi.org/10.1016/j.drup.2011.01.001

Flaherty, C.M., Dodson, S.I., 2005. Effects of pharmaceuticals on Daphnia survival, growth, and reproduction. Chemosphere 61, 200-207. https://doi.org/10.1016/j.chemosphere.2005.02.016

Friedman, M., 2015. Antibiotic-Resistant Bacteria: Prevalence in Food and Inactivation by Food-Compatible Compounds and Plant Extracts. J. Agric. Food Chem. 63, 3805-3822. https://doi.org/10.1021/acs.jafc.5b00778

Friman, V.P., Guzman, L.M., Reuman, D.C., Bell, T., 2015. Bacterial adaptation to sublethal antibiotic gradients can change the ecological properties of multitrophic microbial communities. Proceedings.Biological Sci. / R. Soc. 282, 20142920. https://doi.org/10.1098/rspb.2014.2920

Fussmann, K.E., Schwarzmüller, F., Brose, U., Jousset, A., Rall, B.C., 2014. Ecological stability in response to warming. Nat. Clim. Chang. 4, 206-210. https://doi.org/10.1038/nclimate2134

García-Galán, M.J., Villagrasa, M., Díaz-Cruz, M.S., Barceló, D., 2010. LC-QqLIT MS analysis of nine sulfonamides and one of their acetylated metabolites in the Llobregat River basin. Quantitative determination and qualitative evaluation by IDA experiments. Anal. Bioanal. Chem. 397, 1325-1334. https://doi.org/https://doi.org/10.1007/s00216010-3630-y

Giger, W., Alder, A.C., Golet, E.M., Kohler, H.-P.E., McArdell, C.S., Molnar, E., Siegrist, H., Suter, M.J.-F., 2003. Occurrence and Fate of Antibiotics as Trace Contaminants in Wastewaters, Sewage Sludges, and Surface Waters. Chim. Int. J. Chem. 57, 485-491. https://doi.org/10.2533/000942903777679064

Ginebreda, A., Muñoz, I., de Alda, M.L., Brix, R., López-Doval, J., Barceló, D., 2010. Environmental risk assessment of pharmaceuticals in rivers: relationships between 
hazard indexes and aquatic macroinvertebrate diversity indexes in the Llobregat River (NE Spain). Environ. Int. 36, 153-162. https://doi.org/10.1016/j.envint.2009.10.003

González-Pleiter, M., Gonzalo, S., Rodea-Palomares, I., Leganés, F., Rosal, R., Boltes, K., Marco, E., Fernández-Piñas, F., 2013. Toxicity of five antibiotics and their mixtures towards photosynthetic aquatic organisms: Implications for environmental risk assessment. Water Res. 47, 2050-2064. https://doi.org/10.1016/j.watres.2013.01.020

Grenni, P., Ancona, V., Barra Caracciolo, A., 2018. Ecological effects of antibiotics on natural ecosystems: A review. Microchem. J. 136. https://doi.org/10.1016/j.microc.2017.02.006

Greulich, P., Scott, M., Evans, M.R., Allen, R.J., 2015. Growth-dependent bacterial susceptibility to ribosome-targeting antibiotics. Mol. Syst. Biol. 11, 796-796. https://doi.org/10.15252/msb.20145949

Gullberg, E., Albrecht, L.M., Karlsson, C., Gullberg, E., Albrecht, L.M., Karlsson, C., Sandegren, L., Andersson, D.I., 2014. Selection of a Multidrug Resistance Plasmid by Sublethal Levels of Antibiotics and Heavy Metals. MBio 5, 19-23. https://doi.org/10.1128/mBio.01918-14.Editor

Gullberg, E., Cao, S., Berg, O.G., Ilbäck, C., Sandegren, L., Hughes, D., Andersson, D.I., 2011. Selection of resistant bacteria at very low antibiotic concentrations. PLoS Pathog 7, e1002158. https://doi.org/10.1371/journal.ppat.1002158

Guo, J., Li, J., Chen, H., Bond, P.L., Yuan, Z., 2017. Metagenomic analysis reveals wastewater treatment plants as hotspots of antibiotic resistance genes and mobile genetic elements. Water Res. 123, 468-478. https://doi.org/10.1016/j.watres.2017.07.002

Halling-Sørensen, B., Lützhøft, H.-C.H., Andersen, H.R., Ingerslev, F., 2000. Environmental risk assessment of antibiotics: comparison of mecillinam, trimethoprim and ciprofloxacin. J. Antimicrob. Chemother. 46, 53-58. 

https://doi.org/10.1093/jac/46.suppl_1.53

2 Heise, J., Höltge, S., Schrader, S., Kreuzig, R., 2006. Chemical and biological characterization of non-extractable sulfonamide residues in soil. Chemosphere 65 , 2352-2357. https://doi.org/10.1016/j.chemosphere.2006.04.084

Hiltunen, T., Virta, M., Laine, A.-L., 2017. Antibiotic resistance in the wild: an ecoevolutionary perspective. Philos. Trans. R. Soc. B Biol. Sci. 372, 20160039. https://doi.org/10.1098/rstb.2016.0039

Hoffman, L.R., D’Argenio, D.A., MacCoss, M.J., Zhang, Z., Jones, R.A., Miller, S.I., 2005. Aminoglycoside antibiotics induce bacterial biofilm formation. Nature 436, 1171-1175.

Hughes, S.R., Kay, P., Brown, L.E., 2012. Global synthesis and critical evaluation of pharmaceutical data sets collected from river systems. Environ. Sci. Technol. 47, 661677. https://doi.org/10.1021/es3030148

Isidori, M., Lavorgna, M., Nardelli, A., Pascarella, L., Parrella, A., 2005. Toxic and genotoxic evaluation of six antibiotics on non-target organisms. Sci. Total Environ. 346, 87-98. https://doi.org/10.1016/j.scitotenv.2004.11.017

Jackson, M.C., Loewen, C.J.G., Vinebrooke, R.D., Chimimba, C.T., 2016. Net effects of multiple stressors in freshwater ecosystems: a meta- analysis. Glob. Chang. Biol. 22, 180-189. https://doi.org/10.1111/gcb.13028

Jjemba, P.K., 2006. Excretion and ecotoxicity of pharmaceutical and personal care products in the environment. Ecotoxicol. Environ. Saf. 63, 113-130. https://doi.org/10.1016/j.ecoenv.2004.11.011

Klein, E.Y., Van Boeckel, T.P., Martinez, E.M., Pant, S., Gandra, S., Levin, S.A., Goossens, H., Laxminarayan, R., 2018. Global increase and geographic convergence in antibiotic consumption between 2000 and 2015. Proc. Natl. Acad. Sci. 201717295. https://doi.org/10.1073/pnas.1717295115 
1 Kümmerer, K., 2009. Antibiotics in the aquatic environment-a review-part I. Chemosphere 75, 417-434. https://doi.org/10.1016/j.chemosphere.2008.11.086

Kümmerer, K., 2004. Resistance in the environment. J. Antimicrob. Chemother. 54, 311-320. https://doi.org/10.1093/jac/dkh325

Kümmerer, K., Henninger, A., 2003. Promoting resistance by the emission of antibiotics from hospitals and households into effluent. Clin. Microbiol. Infect. 9, 1203-1214. https://doi.org/10.1111/j.1469-0691.2003.00739.x

Laverman, A.M., Cazier, T., Yan, C., Roose-Amsaleg, C., Petit, F., Garnier, J., Berthe, T., 2015. Exposure to vancomycin causes a shift in the microbial community structure without affecting nitrate reduction rates in river sediments. Environ. Sci. Pollut. Res. 22, 13702-13709. https://doi.org/10.1007/s11356-015-4159-6

Lawrence, D., Fiegna, F., Behrends, V., Bundy, J.G., Phillimore, A.B., Bell, T., Barraclough, T.G., 2012. Species interactions alter evolutionary responses to a novel environment. PLoS Biol 10, e1001330. https://doi.org/10.1371/journal.pbio.1001330

Le Page, G., Gunnarsson, L., Snape, J., Tyler, C.R., 2017. Integrating human and environmental health in antibiotic risk assessment: A critical analysis of protection goals, species sensitivity and antimicrobial resistance. Environ. Int. 109, 155-169. https://doi.org/10.1016/j.envint.2017.09.013

Lewandowski, J., Putschew, A., Schwesig, D., Neumann, C., Radke, M., 2011. Fate of organic micropollutants in the hyporheic zone of a eutrophic lowland stream: Results of a preliminary field study. Sci. Total Environ. 409, 1824-1835. https://doi.org/10.1016/j.scitotenv.2011.01.028

Li, D., Yang, M., Hu, J., Ren, L., Zhang, Y., Li, K., 2008. Determination and fate of oxytetracycline and related compounds in oxytetrac. Environ. Toxicol. 27, 80-86. 
Resistance Genes and Antibiotic Residues in Waste - water and Soil Adjacent to Swine Feedlots : Potential Transfer to Agricultural Lands 1144-1149.

Lindsey, M.E., Meyer, M., Thurman, E.M., 2001. Analysis of Trace Levels of Sulfonamide and Tetracycline Antimicrobials in Groundwater and Surface Water Using Solid-Phase Extraction and Liquid Chromatography/Mass Spectrometry. October 73, 4640-4646. https://doi.org/10.1021/ac010514w

López-Roldán, R., de Alda, M.L., Gros, M., Petrovic, M., Martín-Alonso, J., Barceló, D., 2010. Advanced monitoring of pharmaceuticals and estrogens in the Llobregat River basin (Spain) by liquid chromatography-triple quadrupole-tandem mass spectrometry in combination with ultra performance liquid chromatography-time of flight-mass spectrometry. Chemosphere 80, 1337-1344. https://doi.org/10.1016/j.chemosphere.2010.06.042

Lundström, S. V., Östman, M., Bengtsson-Palme, J., Rutgersson, C., Thoudal, M., Sircar, T., Blanck, H., Eriksson, K.M., Tysklind, M., Flach, C.F., Larsson, D.G.J., 2016. Minimal selective concentrations of tetracycline in complex aquatic bacterial biofilms. Sci. Total Environ. 553, 587-595. https://doi.org/10.1016/j.scitotenv.2016.02.103

Madikizela, L.M., Tavengwa, N.T., Chimuka, L., 2017. Status of pharmaceuticals in African water bodies: Occurrence, removal and analytical methods. J. Environ. Manage. 193, 211-220. https://doi.org/10.1016/j.jenvman.2017.02.022

Managaki, S., Murata, A., Takada, H., Bui, C.T., Chiem, N.H., 2007. Distribution of macrolides, sulfonamides, and trimethoprim in tropical waters: Ubiquitous occurrence of veterinary antibiotics in the Mekong Delta. Environ. Sci. Technol. 41, 8004-8010. https://doi.org/10.1021/es0709021

Martínez, J.L., Rojo, F., 2011. Metabolic regulation of antibiotic resistance. FEMS Microbiol. Rev. 35, 768-789. https://doi.org/10.1111/j.1574-6976.2011.00282.x 
1 McCormick, A., Hoellein, T.J., Mason, S.A., Schluep, J., Kelly, J.J., 2014. Microplastic is an abundant and distinct microbial habitat in an urban river. Environ. Sci. Technol. 48, 11863-11871. https://doi.org/10.1021/es503610r

Molander, L., Ågerstrand, M., Rudén, C., 2009. WikiPharma-A freely available, easily accessible, interactive and comprehensive database for environmental effect data for pharmaceuticals. Regul. Toxicol. Pharmacol. 55, 367-371. https://doi.org/10.1016/j.yrtph.2009.08.009

Mompelat, S., Le Bot, B., Thomas, O., 2009. Occurrence and fate of pharmaceutical products and by-products, from resource to drinking water. Environ. Int. 35, 803-814. https://doi.org/10.1016/j.envint.2008.10.008

Monteiro, S.C., Boxall, A.B.A., 2015. Occurrence and Fate of Human Pharmaceuticals in the Environment, Reviews of Environmental Contamination and Toxicology. https://doi.org/10.1007/978-3-319-20013-2

Pal, C., Bengtsson-Palme, J., Kristiansson, E., Larsson, D.G.J., 2015. Co-occurrence of resistance genes to antibiotics, biocides and metals reveals novel insights into their coselection potential. BMC Genomics 16, 1-14. https://doi.org/10.1186/s12864-015-21535

Peralta-Maraver, I., Galloway, J., Posselt, M., Arnon, S., Reiss, J., Lewandowski, J., Robertson, A.L., 2018a. Environmental filtering and community delineation in the streambed ecotone. Sci. Rep. 8, 1-11. https://doi.org/10.1038/s41598-018-34206-z

Peralta-Maraver, I., Reiss, J., Robertson, A.L., 2018b. Interplay of hydrology, community ecology and pollutant attenuation in the hyporheic zone. Sci. Total Environ. 610-611, 267-275. https://doi.org/10.1016/j.scitotenv.2017.08.036

Perkins, D.M., Bailey, R.A., Dossena, M., Gamfeldt, L., Reiss, J., Trimmer, M., Woodward, G., 2015. Higher biodiversity is required to sustain multiple ecosystem processes across 
temperature regimes. Glob. Chang. Biol. 21, 396-406. https://doi.org/10.1111/gcb.12688

Petrie, B., Barden, R., Kasprzyk-Hordern, B., 2014. A review on emerging contaminants in wastewaters and the environment: Current knowledge, understudied areas and recommendations for future monitoring. Water Res. 72, 3-27. https://doi.org/10.1016/j.watres.2014.08.053

Piddock, L.J. V, 2012. The crisis of no new antibiotics—what is the way forward? Lancet Infect. Dis. 12, 249-253. https://doi.org/10.1016/S1473-3099(11)70316-4

Proia, L., Lupini, G., Osorio, V., Pérez, S., Barceló, D., Schwartz, T., Amalfitano, S., Fazi, S., Romaní, A.M., Sabater, S., 2013. Response of biofilm bacterial communities to antibiotic pollutants in a Mediterranean river. Chemosphere 92, 1126-1135. https://doi.org/10.1016/j.chemosphere.2013.01.063

Quinlan, E.L., Nietch, C.T., Blocksom, K., Lazorchak, J.M., Batt, A.L., Griffiths, R., Klemm, D.J., 2011. Temporal dynamics of periphyton exposed to tetracycline in stream mesocosms. Environ. Sci. Technol. 45, 10684-10690. https://doi.org/10.1021/es202004k

Reiss, J., Bridle, J.R., Montoya, J.M., Woodward, G., 2009. Emerging horizons in biodiversity and ecosystem functioning research. Trends Ecol. Evol. 24, 505-514.

Reiss, J., Schmid-Araya, J.M., 2011. Feeding response of a benthic copepod to ciliate prey type, prey concentration and habitat complexity. Freshw. Biol. 56, 1519-1530. https://doi.org/10.1111/j.1365-2427.2011.02590.x

Reiss, J., Schmid-Araya, J.M., 2010. Life history allometries and production of small fauna. Ecology 91, 497-507. https://doi.org/10.1890/08-1248.1

Robertson, A.L., Wood, P.J., 2010. Ecology of the hyporheic zone: origins, current knowledge and future directions. Fundam. Appl. Limnol. / Arch. für Hydrobiol. 176, 
Robinson, A.A., Belden, J.B., Lydy, M.J., 2005. Toxicity of fluoroquinolone antibiotics to aquatic organisms. Environ. Toxicol. Chem. 24, 423-430. https://doi.org/10.1897/04210R.1

Rodriguez-Mozaz, S., Chamorro, S., Marti, E., Huerta, B., Gros, M., Sànchez-Melsió, A., Borrego, C.M., Barceló, D., Balcázar, J.L., 2015. Occurrence of antibiotics and antibiotic resistance genes in hospital and urban wastewaters and their impact on the receiving river. Water Res. 69, 234-242. https://doi.org/10.1016/j.watres.2014.11.021

Schwartz, T., 2003. Detection of antibiotic-resistant bacteria and their resistance genes in 43.

Segura, P.A., Takada, H., Correa, J.A., El Saadi, K., Koike, T., Onwona-Agyeman, S., Ofosu-Anim, J., Sabi, E.B., Wasonga, O. V., Mghalu, J.M., dos Santos Junior, A.M., Newman, B., Weerts, S., Yargeau, V., 2015. Global occurrence of anti-infectives in contaminated surface waters: Impact of income inequality between countries. Environ. Int. 80, 1386-1398. https://doi.org/10.1016/j.envint.2015.04.001

Singer, A.C., Shaw, H., Rhodes, V., Hart, A., 2016. Review of antimicrobial resistance in the environment and its relevance to environmental regulators. Front. Microbiol. 7, 1-22. https://doi.org/10.3389/fmicb.2016.01728

Soares, J., Castro, L.F.C., Reis-Henriques, M.A., Monteiro, N.M., Santos, M.M., 2012. Zebrafish (Danio rerio) life-cycle exposure to chronic low doses of ethinylestradiol modulates p53 gene transcription within the gonads, but not NER pathways. Ecotoxicology 21, 1513-1522. https://doi.org/10.1007/s10646-012-0905-4

Tamminen, M., Virta, M., Fani, R., Fondi, M., 2012. Large-scale analysis of plasmid relationships through gene-sharing networks. Mol. Biol. Evol. 29, 1225-1240. https://doi.org/10.1093/molbev/msr292

Thompson, M.S.A., Bankier, C., Bell, T., Dumbrell, A.J., Gray, C., Ledger, M.E., Lehmann, 
K., McKew, B.A., Sayer, C.D., Shelley, F., 2015. Gene- to- ecosystem impacts of a catastrophic pesticide spill: testing a multilevel bioassessment approach in a river ecosystem. Freshw. Biol. https://doi.org/10.1111/fwb.12676

Välitalo, P., Massei, R., Heiskanen, I., Behnisch, P., Brack, W., Tindall, A.J., Du Pasquier, D., Küster, E., Mikola, A., Schulze, T., Sillanpää, M., 2017. Effect-based assessment of toxicity removal during wastewater treatment. Water Res. 126, 153-163. https://doi.org/10.1016/j.watres.2017.09.014

Van Boeckel, T.P., Gandra, S., Ashok, A., Caudron, Q., Grenfell, B.T., Levin, S.A., Laxminarayan, R., 2014. Global antibiotic consumption 2000 to 2010: an analysis of national pharmaceutical sales data. Lancet Infect. Dis. 14, 742-750. https://doi.org/10.1016/S1473-3099(14)70780-7

Wales, A., Davies, R., 2015. Co-Selection of Resistance to Antibiotics, Biocides and Heavy Metals, and Its Relevance to Foodborne Pathogens. Antibiotics 4, 567-604. https://doi.org/10.3390/antibiotics4040567

Watkinson, A.J., Micalizzi, G.B., Graham, G.M., Bates, J.B., Costanzo, S.D., 2007. Antibiotic-resistant Escherichia coli in wastewaters, surface waters, and oysters from an urban riverine system. Appl. Environ. Microbiol. 73, 5667-5670. https://doi.org/AEM.00763-07

Wise, R., 2002. Antimicrobial resistance: priorities for action. J. Antimicrob. Chemother. 49, 585-586. https://doi.org/10.1093/jac/49.4.585

Yeung, A.T., Bains, M., Hancock, R.E., 2011. The sensor kinase CbrA is a global regulator that modulates metabolism, virulence, and antibiotic resistance in Pseudomonas aeruginosa. J. Bacteriol. 193, 918-931. https://doi.org/10.1128/JB.00911-10 


\section{Figure legends}

2 Fig. 1. Ecotoxicity $\left(\mathrm{EC}_{50}\right)$ of antibiotics, based on bioassays published in the database

3 Wikipharma, for unicellular organisms (panel A) and for multicellular organisms (panel B).

4 The responses measured were both chronic (e.g. growth inhibition, bioluminescence) and

5 acute (e.g. death, survival) and are given in the electronic supplementary material Table S2.

6 Only antibiotics used in at least 3 bioassays are represented. Boxes show interquartile range

7 and median, whiskers show range and outliers. The widths of the boxes vary with the number

8 of experiments (n). The red lines indicate the toxicity level: the Commission of the European

9 Communities classifies chemicals with an $\mathrm{EC}_{50}$ between 10 and $100 \mathrm{mg} / \mathrm{L}$ as harmful, from 1

10 to $10 \mathrm{mg} / \mathrm{L}$ as toxic and those under $1 \mathrm{mg} / \mathrm{L}$ as very toxic to aquatic organisms (European

11 Commission, 1996; Petrie et al., 2014). The black triangles represent the highest concentrations of the antibiotic as found in fresh water (see Table 1).

Fig. 2. Possible effects of antibiotics and multiple stressors in freshwater ecosystems on a simple freshwater food web (bacteria, algae, a protist and a micro-crustacean). Arrows indicate trophic links between species (thin arrow: normal prey-to-predator ratio, thick arrow: destabilised prey-to-predator ratio). Left hand side panel: the food web without external stressors. Middle panel: the effect of a single antibiotic that might induce the death of one strain of bacteria and the resistance of another one, impacting the whole food web by changing the trophic links. The right-hand side panels show three further scenarios when more stressors are added such as: other antibiotics (the effect of a cocktail of antibiotics might induce stronger and additive effects on both bacteria and algae), or warming (the effect of antibiotics coupled with the effect of warming might induce an increase of the organisms' metabolic rates and therefore a quicker resistance for some bacteria), or warming and other antibiotics together. 